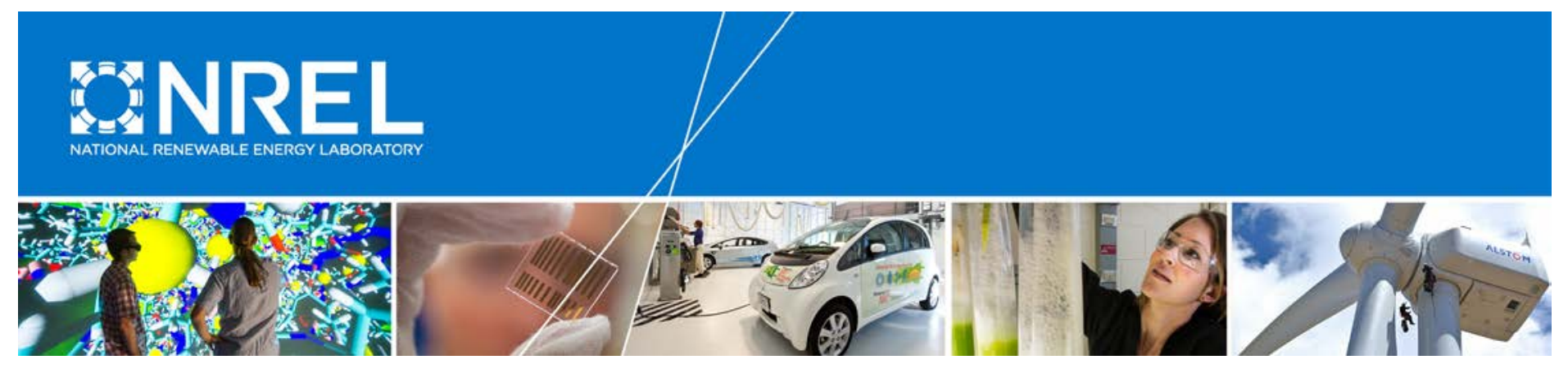

\title{
Can Wind Farms in Inner Mongolia Affect the Air Quality in Beijing?
}

Julie K. Lundquist

University of Colorado and National Renewable Energy Laboratory

Joseph C.-Y. Lee University of Colorado

Caroline Draxl and Patrick Moriarty National Renewable Energy Laboratory

Shreyas Ananthan, Feng Zhang, and Heng Li Envision USA, LTD

NREL is a national laboratory of the U.S. Department of Energy Office of Energy Efficiency \& Renewable Energy Operated by the Alliance for Sustainable Energy, LLC

This report is available at no cost from the National Renewable Energy Laboratory (NREL) at www.nrel.gov/publications.

Technical Report

NREL/TP-5000-65925

April 2016 


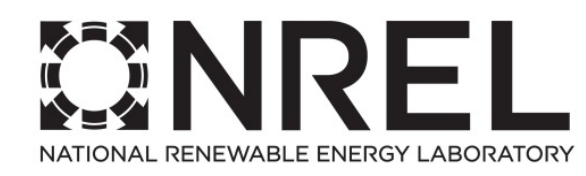

\section{Can Wind Farms in Inner Mongolia Affect the Air Quality in Beijing?}

Julie K. Lundquist

University of Colorado and National Renewable Energy Laboratory

Joseph C.-Y. Lee

University of Colorado

Caroline Draxl and Patrick Moriarty National Renewable Energy Laboratory

Shreyas Ananthan, Feng Zhang, and Heng Li Envision USA, LTD

Prepared for Envision Energy USA, LTD through Technical Services Agreement TSA-15-739

NREL is a national laboratory of the U.S. Department of Energy Office of Energy Efficiency \& Renewable Energy Operated by the Alliance for Sustainable Energy, LLC

This report is available at no cost from the National Renewable Energy Laboratory (NREL) at www.nrel.gov/publications.

National Renewable Energy Laboratory 15013 Denver West Parkway Golden, CO 80401 303-275-3000 • www.nrel.gov
Technical Report

NREL/TP-5000-65925

April 2016

Contract No. DE-AC36-08G028308 


\section{NOTICE}

This report was prepared as an account of work sponsored by an agency of the United States government. Neither the United States government nor any agency thereof, nor any of their employees, makes any warranty, express or implied, or assumes any legal liability or responsibility for the accuracy, completeness, or usefulness of any information, apparatus, product, or process disclosed, or represents that its use would not infringe privately owned rights. Reference herein to any specific commercial product, process, or service by trade name, trademark, manufacturer, or otherwise does not necessarily constitute or imply its endorsement, recommendation, or favoring by the United States government or any agency thereof. The views and opinions of authors expressed herein do not necessarily state or reflect those of the United States government or any agency thereof.

This report is available at no cost from the National Renewable Energy Laboratory (NREL) at www.nrel.gov/publications.

Available electronically at SciTech Connect http:/www.osti.gov/scitech

Available for a processing fee to U.S. Department of Energy and its contractors, in paper, from:

U.S. Department of Energy

Office of Scientific and Technical Information

P.O. Box 62

Oak Ridge, TN 37831-0062

OSTI http://www.osti.gov

Phone: 865.576.8401

Fax: 865.576.5728

Email: reports@osti.gov

Available for sale to the public, in paper, from:

U.S. Department of Commerce

National Technical Information Service

5301 Shawnee Road

Alexandra, VA 22312

NTIS http://www.ntis.gov

Phone: 800.553 .6847 or 703.605 .6000

Fax: 703.605.6900

Email: orders@ntis.gov 


\section{Table of Contents}

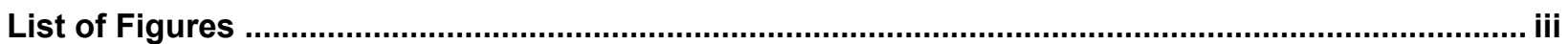

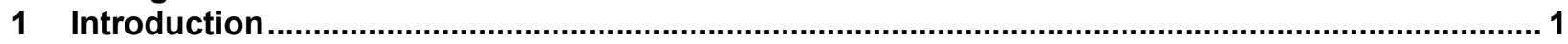

2 Summary of Observations of Wind Farm Wakes ..................................................................... 2

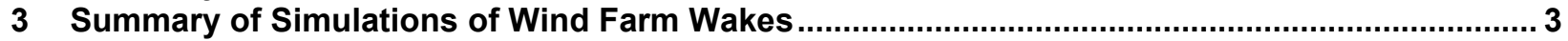

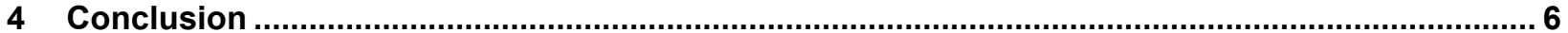

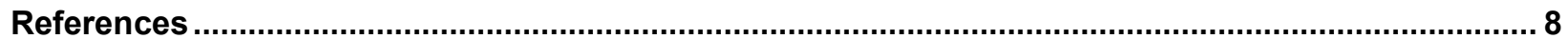

\section{List of Figures}

Figure 1. RADARSAT-2 intensity map of the southern North Sea observed April 30, 2013, at 17:41 UTC; the blue lines indicate wind farms and the red arrows show the path of the wind farm wake (Hasager et al. [2015]).

Figure 2. Plan view (left) and vertical slice (right) of the wind farm wake wind speed deficit from a 500-MW wind farm during nocturnal hours (Fitch et al. [2013a]) ............................................... 3

Figure 3. Difference in $80-\mathrm{m}$ wind speed from a WRF simulation with and without a wind farm. Turbines are represented by cyan circles in the center of the domain ....................................... 4

Figure 4. Mean wintertime (DJF) differences in 10-m winds $\left(\mathrm{m} \mathrm{s}^{-1}\right)$ between the simulations with and without $220 \mathrm{GW}$ of wind deployment in Europe; regions with a 95\% confidence level of the differences are indicated by dots (Vautard et al. [2014]) ure 5. Relationship between wind direction and Beijing's PM 2.5 levels, reprinted from Beam (2015), attributed to Greenpeace's Lauri Myllyvirta.. 


\section{Introduction}

China leads the world with the greatest deployment of wind turbines for renewably generated electricity. At the end of 2014, the country had installed 114 gigawatts (GW) of wind turbines, with $22 \mathrm{GW}$ deployed in Inner Mongolia and another $10 \mathrm{GW}$ in neighboring Gansu (GWEC 2015). Wind-generated electricity accounted for $2.78 \%$ of national electricity consumption in 2014 , contributing electricity to the grid without releasing either the particulate matter that causes air pollution or carbon dioxide emissions that exacerbate global warming. Rumors suggest that the wind farms of Inner Mongolia might worsen air quality in Beijing by "slowing" the winds in this area. These Inner Mongolian wind farms are located at least 200 kilometers $(\mathrm{km})$ from Beijing. Presumably, this rumor suggests that without the presence of wind farms upwind from Beijing, stronger winds might blow air pollutants out of the urban area. Therefore, a team of researchers from the University of Colorado Boulder and the National Renewable Energy Laboratory investigated whether or not large wind farms can reasonably be expected to slow winds from up to $200 \mathrm{~km}$ away.

Wind turbines generate electricity by extracting momentum from the lower atmosphere. This momentum fundamentally originates from large-scale pressure gradients, driven by global imbalances in surface heating. Equatorial regions receive more solar radiation than the poles, thereby creating large-scale circulation patterns that result in winds. As these winds enter the region of a wind turbine's rotor disk, some of the wind's momentum turns the blades, generating electricity. Immediately downwind of wind turbines, a "wake" region of slower air occurs, and this wake gradually entrains faster-moving air from the local environment so that the wake erodes further downwind. When the large-scale pressure gradient supports only very slow winds (below about 2.5 meters per second $\left(\mathrm{m} \mathrm{s}^{-1}\right)$ ), wind turbines do not generate any power and therefore do not generate wakes.

On a grander scale, clusters of wind turbines will generate a larger region of slower air downwind, and this "wind farm" wake will also erode as it propagates downwind, entraining faster-moving air driven by large-scale pressure gradients. A wake is stronger and persists further downwind during stable nighttime conditions over flat terrain when little or no ambient background turbulence is present to erode the wake. During the day, or over complex and mountainous terrain, turbulence will mix the wake with faster winds so that it becomes diluted and indistinguishable from the environment, just as a plume of smoke will become undetectable as it mixes with cleaner ambient air. Observations and simulations of wind farm wakes suggest that, at maximum, detectable regions of slower air $\left(0.10 \mathrm{~m} \mathrm{~s}^{-1}\right.$ slower than surrounding air speeds) occur in the local region around a wind farm. This analysis of existing published scientific work suggests that a wind farm wake is not detectable further than $100 \mathrm{~km}$ from a wind farm and is in fact usually constrained to a much smaller region close to the wind turbines. This localized reduction, or deficit, of wind speed is not related to the large-scale pressure gradient that determines the strengths of winds in regions hundreds of kilometers away. Herein, we first discuss observations of wind farm wakes and then survey existing modeling studies that address the concept of wind farms affecting winds far downwind. 


\section{Summary of Observations of Wind Farm Wakes}

Observations of wind turbine wakes, or regions of slower wind downwind of wind turbines, can suggest how far downwind the effects of wind turbines can be distinguished from ambient variability in the background flow (the background flow is determined by the pressure gradients over large regions.) To date, most observations of full wind farm wakes have been made for offshore wind farms in Europe. Because the offshore surface is smoother than the surface of land, offshore wakes are stronger and represent a worst-case scenario of a wake; land-based wakes would generally be expected to erode faster. Satellite Synthetic Aperture Radar observations of the wind speed at the water's surface were first used to identify wind farm wakes. Recent observations of the wakes of 10 large wind farms in the North Sea can help constrain the distance downwind where a wake would be expected to persist (Hasager et al. 2015).

The 165-megawatt (MW) Belwind farm generated a wake detectable in 10-m wind speeds $55 \mathrm{~km}$ downwind (Figure 1), although by $30 \mathrm{~km}$ downwind, the wind speed reduction in the wake was of similar size to the ambient variability in the flow (the 10-m altitude is typical of air quality sensors.) The analyses conducted by Hasager et al. (2015) of this and other cases of many different sizes of wind farms suggest that a wind speed deficit of $0.25 \mathrm{~m} \mathrm{~s}^{-1}$ at $10-\mathrm{m}$ altitude is constrained to a distance of about $5 \mathrm{~km}$ from the wind farm, much less than the 200-km distance between Inner Mongolia and Beijing. By $12 \mathrm{~km}$ downwind, a wind speed deficit of only $0.15 \mathrm{~m}$ $\mathrm{s}^{-1}$ occurs. In conditions of complex terrain, such as the Yanshan and Taihang mountain rangeswhich separate Inner Mongolia from Beijing-wakes would likely be disrupted at a much smaller distance.

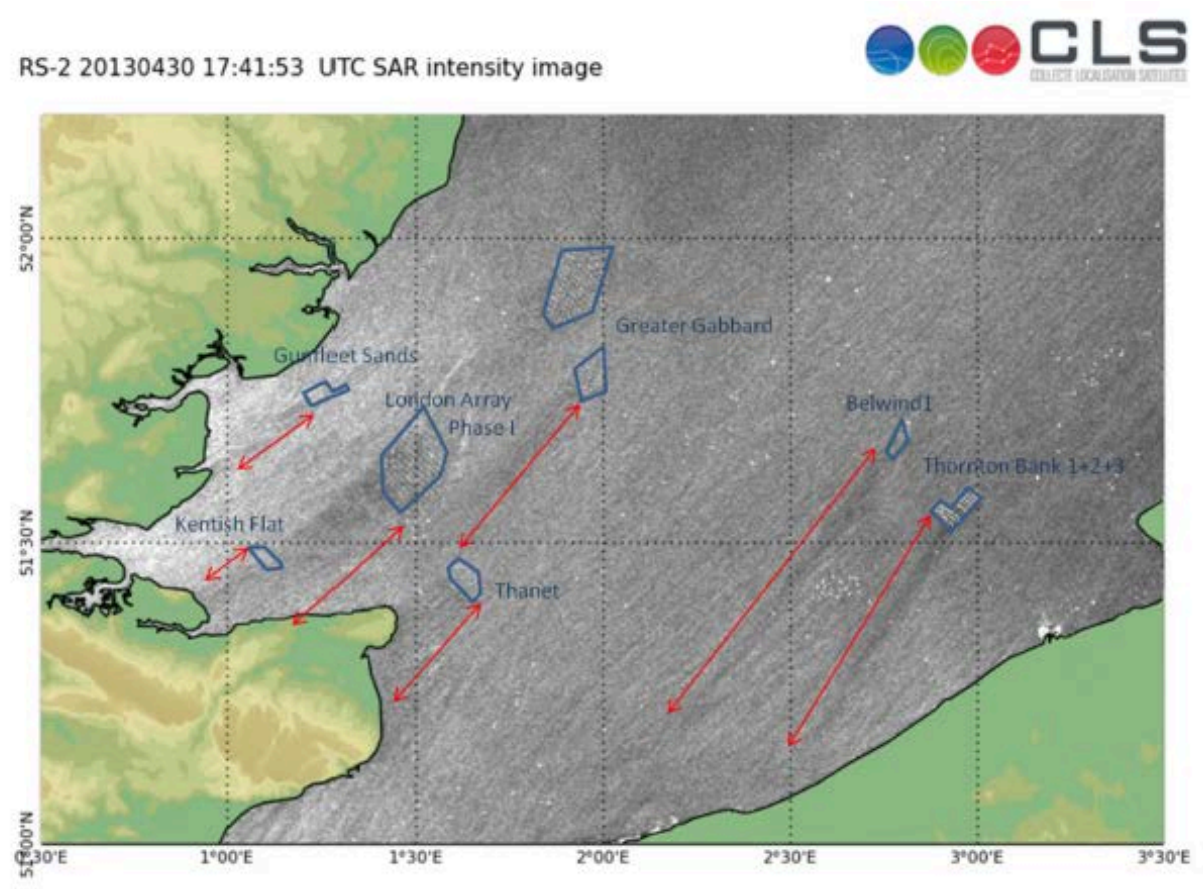

Figure 1. RADARSAT-2 intensity map of the southern North Sea observed April 30, 2013, at 17:41 UTC; the blue lines indicate wind farms and the red arrows show the path of the wind farm wake (Hasager et al. [2015]) 


\section{Summary of Simulations of Wind Farm Wakes}

The physical effects of wind farms can be incorporated into numerical weather prediction simulations to provide simulation-based estimates of the extent of wind farm wakes. Several approaches to representing these effects in weather and climate models have been compared (Fitch et al. 2013b; Fitch 2015), concluding that simplistic approaches of increasing the roughness of the surface (e.g., Keith et al. 2004) likely overestimate the effects of wind farms. A preferred approach is to employ an elevated drag approach (Baidya Roy 2011; Fitch et al. 2012; Jacobson and Archer 2012; Adams and Keith 2013), in which momentum is removed from the atmosphere at the height of the wind turbine rotor disk.

In land-based simulations of flat prairie grassland, Fitch et al. (2013a) employed this elevated drag approach and demonstrated that, in stable nighttime conditions, the wind farm wake deficit of $10 \%$ of the ambient wind speed (or, in this case, a deficit of $1.5 \mathrm{~m} \mathrm{~s}^{-1}$ ) can extend $60 \mathrm{~km}$ downwind (Figure 2a), while this wind speed deficit is confined to the lower atmosphere, extending only $\sim 100 \mathrm{~m}$ above the wind turbines themselves (Figure2b). During the day, vigorous convectively driven turbulence erodes wakes quickly, and daytime wakes have a much smaller horizontal extent. Although the modeling domain of Fitch et al. (2013a) was not large enough to span the distance from Inner Mongolia to Beijing, the strongest wakes simulated eroded to wind speed deficits $<0.2 \mathrm{~m} \mathrm{~s}^{-1}$ by $100 \mathrm{~km}$ downwind. In a later study based on an actual 300-MW wind farm in Iowa, including very subtle topography, simulations suggest that a wind speed deficit of $1 \mathrm{~m} \mathrm{~s}^{-1}$ occurs only within $\sim 25 \mathrm{~km}$ of the farm, only during stable nighttime conditions (Figure 3). If such wind speed deficits were blown into the mountainous regions of Yanshan and Taihang, they would be rapidly mixed out by complex flows caused by the mountainous terrain.

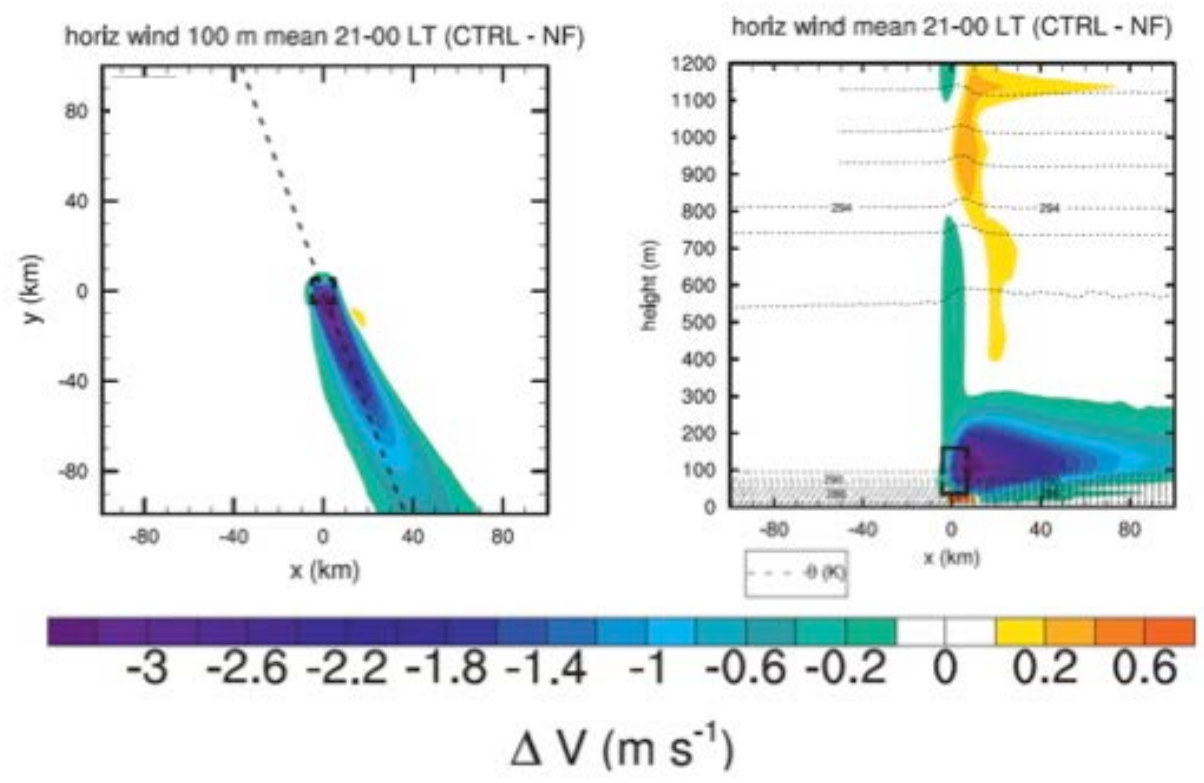

Figure 2. Plan view (left) and vertical slice (right) of the wind farm wake wind speed deficit from a 500-MW wind farm during nocturnal hours (Fitch et al. [2013a]) 
Figure 3. Difference in 80-m wind speed from a WRF simulation with and without a wind farm. Turbines are represented by cyan circles in the center of the domain

In a more comprehensive continental-scale modeling study exploring large-scale wind deployment, Vautard et al. (2014) explored the weather and climate impacts of projected 2020 European wind energy, or $220 \mathrm{GW}$ (deployment in all of China at the end of 2014 was $114 \mathrm{GW}$, with $22 \mathrm{GW}$ in Inner Mongolia.) They found that such scale of deployment, which is five times larger than the current deployment in Inner Mongolia, can induce minor changes in average atmospheric circulation. These small shifts result in subtle changes in wintertime temperature $(0.3 \mathrm{~K})$ and precipitation $(0.15 \mathrm{~mm})$ in some parts of Europe. The wintertime changes in temperature and precipitation introduced by the wind farms were small compared to interannual variability in temperature and precipitation. Summertime responses were even smaller and not significant. Throughout Europe, even in the immediate vicinity of wind farms, Vautard et al. (2014) found that mean wintertime (December-January-February [DJF]) 10-m wind speed decreases by less than $0.10 \mathrm{~m} \mathrm{~s}^{-1}$ (Figure 4). Given the complex terrain around Inner Mongolia and Beijing, we would expect similarly small impacts on winds. 


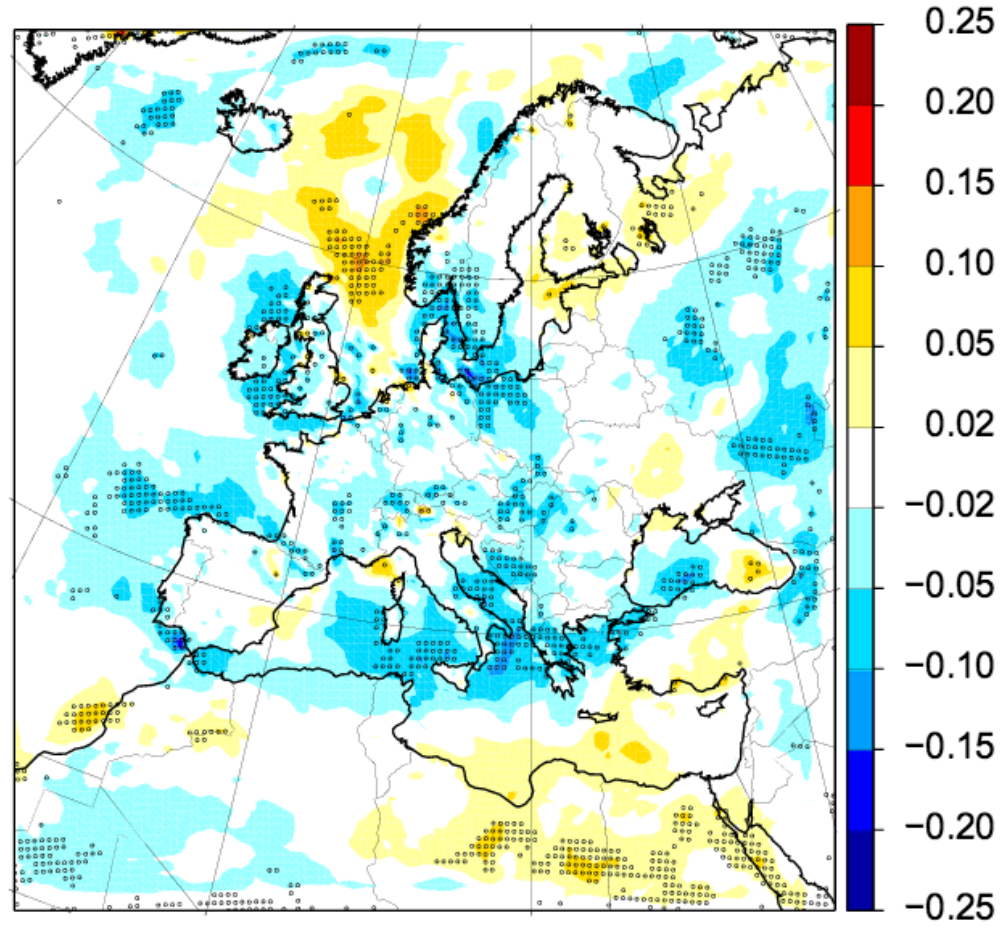

Figure 4. Mean wintertime (DJF) differences in 10-m winds $\left(\mathrm{m} \mathrm{s}^{-1}\right)$ between the simulations with and without $220 \mathrm{GW}$ of wind deployment in Europe; regions with a 95\% confidence level of the differences are indicated by dots (Vautard et al. [2014]) 


\section{Conclusion}

Air quality in Beijing through the winter of 2015-2016 has been remarkably poor, with at least four episodes in November and December 2015 with PM2.5 measurements considered "Beyond Hazardous" (U.S. Department of State, http://www.stateair.net/web/historical/1/1.html). These events are associated with very low wind speeds in the area. Speculation suggests that these air quality episodes occurred because of stagnant or slow winds caused by wind farms in Inner Mongolia, some $220 \mathrm{~km}$ away. Although regions of slower winds downwind of wind farms, or "wind farm wakes," do occur, no observational or simulation-based evidence would suggest that Inner Mongolia wind farm wakes would persist far enough to affect Beijing air quality. Surveys of satellite observations of offshore wind farms wakes show that these wakes may persist up to $30 \mathrm{~km}$ downwind of a wind farm in flat terrain, but would be very unlikely to persist 200 or more km away, especially with mountains or complex terrain between the wind farms and Beijing.

Similarly, simulations created with a state-of-the-art numerical weather prediction model that assume a flat ground with grass cover also suggest that wind farm wakes, at their strongest during stable nighttime conditions, were barely detectable $60 \mathrm{~km}$ away. More realistic simulations that included actual topographic variability and vegetation effects showed detectable wakes only within $25 \mathrm{~km}$ of wind farms. Moreover, even if Beijing was situated closer to Inner Mongolia and experienced those very small wind decreases, a deficit of wind speed caused by wind turbines is certainly much smaller than the large-scale pressure gradients that bring low wind speeds over a broad region (which are responsible for trapping pollutants in a large urban area). Therefore, based both on observations and simulations, we determined that it is extremely unlikely that Beijing's air quality events were caused by, or even influenced by, wind farms slowing the wind. Rather, these air quality events should be attributed to emissions of particulate matter, especially as some studies indicate that these poor air quality events are associated with southerly winds (Figure 5) bringing in pollution from southern industrial provinces (Beam 2015). Reductions in particulate matter emissions can be achieved with increasing reliance on wind and solar energy (Jacobson and High 2008). 


\section{EFFECT OF WIND DIRECTION ON BEIJING'S PM 2.5 LEVELS}

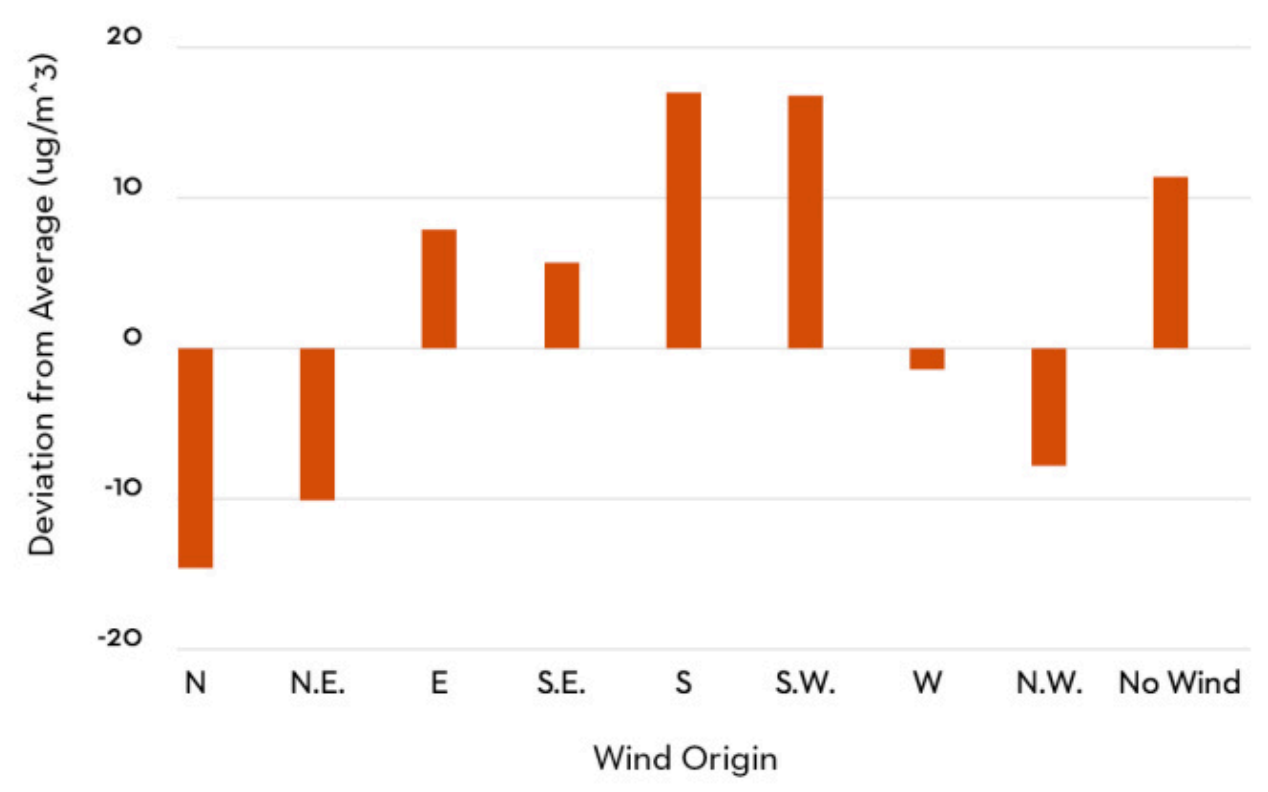

Figure 5. Relationship between wind direction and Beijing's PM 2.5 levels, reprinted from Beam (2015), attributed to Greenpeace's Lauri Myllyvirta

To clearly delineate the effects of the wind farms of Inner Mongolia on specific air quality events, as opposed to the multi-year average effects on winds reported in the studies above, we recommend designing a series of numerical weather prediction simulations of those events using a parameterization of those wind farms. It is extremely unlikely that Inner Mongolian wind farms affect air quality in Beijing, but detailed simulations of these events could identify the source regions for the pollutants, which could suggest pathways forward for resolving air quality concerns in the world's second largest proper city and China's political, cultural, and educational center. 


\section{References}

Adams, A. S., and D. W. Keith, 2013: Are global wind power resource estimates overstated? Environ. Res. Lett., 8, 015021, doi:10.1088/1748-9326/8/1/015021.

Baidya Roy, S., 2011: Simulating impacts of wind farms on local hydrometeorology. J. Wind Eng. Ind. Aerodyn., 99, 491-498, doi:10.1016/j.jweia.2010.12.013.

Beam, C., 2015: China Tries a New Tactic to Combat Pollution: Transparency. The New Yorker, February 6 http://www.newyorker.com/news/news-desk/china-tries-new-tactic-combatpollution-transparency (Accessed February 12, 2016).

Fitch, A. C., 2015: Climate Impacts of Large-Scale Wind Farms as Parameterized in a Global Climate Model. J. Clim., 28, 6160-6180, doi:10.1175/JCLI-D-14-00245.1.

Fitch, A. C., J. B. Olson, J. K. Lundquist, J. Dudhia, A. K. Gupta, J. Michalakes, and I. Barstad, 2012: Local and Mesoscale Impacts of Wind Farms as Parameterized in a Mesoscale NWP Model. Mon. Weather Rev., 140, 3017-3038, doi:10.1175/MWR-D-11-00352.1.

Fitch, A. C., J. K. Lundquist, and J. B. Olson, 2013a: Mesoscale Influences of Wind Farms throughout a Diurnal Cycle. Mon. Weather Rev., 141, 2173-2198, doi:10.1175/MWR-D12-00185.1.

Fitch, A. C., J. B. Olson, and J. K. Lundquist, 2013b: Parameterization of Wind Farms in Climate Models. J. Clim., 26, 6439-6458, doi:10.1175/JCLI-D-12-00376.1.

GWEC, 2015: GWEC - Global Wind Report | Annual Market Update 2014 GWEC_Global_Wind_2014_Report_LR.pdf. http://www.gwec.net/wpcontent/uploads/2015/03/GWEC_Global_Wind_2014_Report_LR.pdf (Accessed February 10, 2016).

Hasager, C., P. Vincent, J. Badger, M. Badger, A. Di Bella, A. Peña, R. Husson, and P. Volker, 2015: Using Satellite SAR to Characterize the Wind Flow around Offshore Wind Farms. Energies, 8, 5413-5439, doi:10.3390/en8065413.

Jacobson, and High, 2008: Wind Energy and Air Emission Reduction Benefits: A Primer. http://www.nrel.gov/docs/fy08osti/42616.pdf.

Jacobson, M. Z., and C. L. Archer, 2012: Saturation wind power potential and its implications for wind energy. Proc. Natl. Acad. Sci., 109, 15679-15684.

Keith, D. W., J. F. DeCarolis, D. C. Denkenberger, D. H. Lenschow, S. L. Malyshev, S. Pacala, and P. J. Rasch, 2004: The influence of large-scale wind power on global climate. Proc. Natl. Acad. Sci. U. S. A., 101, 16115-16120.

Vautard, R., F. Thais, I. Tobin, F.-M. Bréon, J.-G. D. de Lavergne, A. Colette, P. Yiou, and P. M. Ruti, 2014: Regional climate model simulations indicate limited climatic impacts by operational and planned European wind farms. Nat. Commun., 5 , doi:10.1038/ncomms4196. http://www.nature.com/doifinder/10.1038/ncomms4196 (Accessed October 2, 2015). 